\title{
Experimental Verification of 2-Degree-of-Freedom Deadbeat Control with Disturbance Compensation for PMSM Drive System Using FPGA
}

\author{
Arata Takahashi* \\ Student Member, \\ Kazuya Ito* \\ Student Member \\ Kantaro Yoshimoto* Member, \\ Tomoki Yokoyama*a) Member
}

(Manuscript received June 5, 2020, revised Aug. 4, 2020)

J-STAGE Advance published date : Oct. 1, 2020

\begin{abstract}
This paper presents a new control system for permanent magnet synchronous motors composed of a 2-degree-offreedom deadbeat control with a disturbance compensation method using a field-programmable gate array (FPGA). The purpose is to achieve quick response and improve the tracking accuracy of motor current and the robustness against parameter variations. The proposed control system using a FPGA based the hardware controller with simple implementation can compute all calculation process within the dead time of an inverter, realizing ideal real time feedback control without sample delay. The performance of the proposed control strategy was verified in comparison with the conventional deadbeat control method through simulations and experimental results.
\end{abstract}

Keywords: PMSM, FPGA, deadbeat control, 2-degree-of-freedom control, disturbance compensation control

\section{Introduction}

Recently, permanent magnet synchronous motors (PMSMs) are widely used for industry applications, and high responsiveness and robustness against parameters variations of the motor control system are required ${ }^{(1)-(3)}$. In order to meet these requirements, new control methods and approaches for PMSM drive system are studied. As one of ideas, the perfect tracking control method based on the exact model of PMSM to control the over modulation region has been presented ${ }^{(4)-(6)}$. This perfect tracking controller for PMSM showed the good performance of torque response in various operating points as linear region and over modulation region of the inverter pulse width modulation (PWM), compared with another method by switching the several controllers for each region. Because the perfect tracking control method is expanded from linear region of the inverter to over modulation region, realizing the high response characteristics of the motor drive system using the deadbeat control. However, the conventional deadbeat control system can not respond to the load disturbance while PWM carrier interval.

In order to solve this problem, a method of modifying the switching pulse width based on $1 \mathrm{MHz}$ high-speed sampling and high-speed control calculation has been proposed in the previous research, showing the validation results for its effectiveness ${ }^{(7)-(9)}$. But this approach requires high-spec control hardware resources and complex very high speed integrated circuit hardware description language (VHDL) implementation.

This paper proposes 2-degree-of-freedom deadbeat control with a disturbance compensation method. In this proposed

a) Correspondence to: Tomoki Yokoyama. E-mail: t-yoko@mail. dendai.ac.jp

* Tokyo Denki University

5, Asahicho, Senju, Adachiku, Tokyo 120-8551, Japan method, a field-programmable gate array (FPGA) based hardware controller is used for the implementation with simple VHDL configuration. The execution time from the sampling instant of the state variables to the end of the control can be calculated within the dead time of the inverter by the proposed controller. Thus, the proposed controller can realize the ideal discrete time model without sampling compensation method. Using this advantage, the disturbance element to the nominal model can be detected in every sampling instant, the proposed controller can compensate the disturbance by detected value. The performance of the proposed control strategy was verified in comparison with the conventional deadbeat control method and the conventional 2-degree-offreedom deadbeat control method, through simulations and experimental results which showed robustness of the control system and better tracking accuracy.

\section{Motor Drive System}

Figure 1 shows the block diagram of a motor drive system, which is composed by a FPGA based hardware controller, a PWM inverter, an interior permanent magnet synchronous motor (IPMSM) and a load motor using IPMSM also. Phase currents $I_{u}$ and $I_{w}$ are obtained by an analog digital (AD) board through the interface board. The encoder pulse is acquired directly by a FPGA board. The FPGA outputs PWM pulse signals for the inverter to activate each gate switching device. The inverter supplies three-phase voltage to the IPMSM, using DC power supply.

\section{Design of Control Method for PMSM Motor}

3.1 Modeling Figure 2 shows the d-q frame model of PMSM, and (1) shows the circuit equation of PMSM on the d-q frame. 


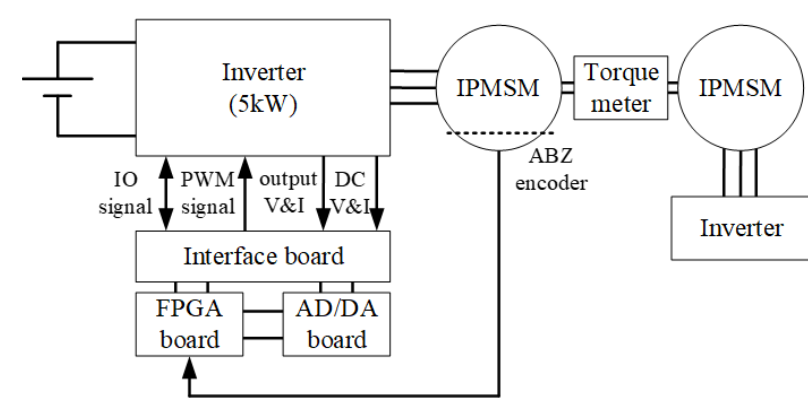

Fig. 1. Diagram of proposed control system

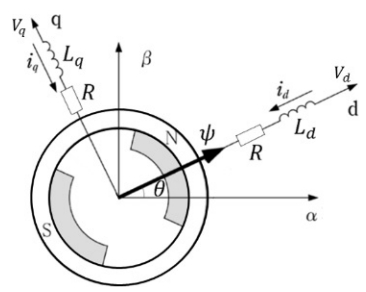

Fig. 2. The d-q frame model of PMSM

$$
\begin{aligned}
& {\left[\begin{array}{l}
V_{d} \\
V_{q}
\end{array}\right]=\left[\begin{array}{cc}
R & -\omega L_{q} \\
\omega L_{d} & R
\end{array}\right]\left[\begin{array}{c}
i_{d} \\
i_{q}
\end{array}\right]+\left[\begin{array}{cc}
L_{d} & 0 \\
0 & L_{q}
\end{array}\right] \frac{d}{d t}\left[\begin{array}{l}
i_{d} \\
i_{q}
\end{array}\right]+\left[\begin{array}{c}
0 \\
\omega \psi
\end{array}\right] .} \\
& \psi \ldots \ldots \ldots \ldots \ldots \ldots(1) \\
& \psi=\sqrt{3 / 2} \phi_{f}
\end{aligned}
$$

$\phi_{f}$ denotes the permanent magnet flux on 3-phase. $\omega$ denotes the electrical angular speed. $L_{d}, L_{q}, \psi, R, V_{d}, V_{q}, i_{d}$ and $i_{q}$ show the d-q axis inductance, permanent magnet flux, stator resistance, $\mathrm{d}$-q-axis stator voltage components and dq-axis stator current components respectively.

3.2 Deadbeat Control (DB) Equation (2) shows the state equation for an IPMSM under the nominal condition on d-q coordination.

$$
\dot{x}=A_{n} x+B_{n} u,
$$

where

$$
\begin{aligned}
& x=\left[\begin{array}{l}
i_{d} \\
i_{q}
\end{array}\right], u=\left[\begin{array}{c}
V_{d} \\
V_{q}-\omega \psi
\end{array}\right], \\
& A_{n}=\left[\begin{array}{cc}
-\frac{R_{n}}{L_{d n}} & \frac{\omega L_{q n}}{L_{d n}} \\
-\frac{\omega L_{d n}}{L_{q n}} & -\frac{R_{n}}{L_{q n}}
\end{array}\right], B_{n}=\left[\begin{array}{cc}
\frac{1}{L_{d n}} & 0 \\
0 & \frac{1}{L_{q n}}
\end{array}\right] .
\end{aligned}
$$

$L_{d n}, L_{q n}$, and $R_{n}$ denote the nominal value of $L_{d}, L_{q}, R$.

It is assumed that the PWM pulse is generated in the center of the carrier period as shown in Fig. 3 and the voltage command $V_{q}, V_{d}$ are held as constant during the sampling interval. The state equation for the discrete time model can be described as follows ${ }^{(8)(11)}$.

$$
x(k+1)=F_{n} x(k)+G_{n} u(k),
$$

where

$$
F_{n}=e^{A_{n} T}, G_{n}=e^{\frac{A_{n} T}{2}} B_{n}
$$

Based on (4), replacing $u(k)$ as $u_{r e f}(k)$ and replacing $x(k+1)$ as $x_{\text {ref }}(k)$, the output voltage command $u_{r e f}(k)$ can be calculated using (6).

$$
u_{r e f}(k)=G_{n}^{-1}\left\{x_{r e f}(k)-F_{n} x(k)\right\},
$$

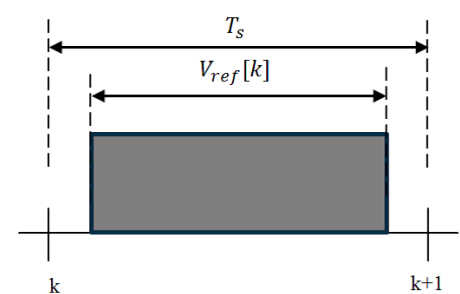

Fig. 3. PWM pulse model for the deadbeat control

where

$$
\begin{aligned}
& {\left[\begin{array}{l}
V_{\text {dref }} \\
V_{\text {qref }}^{\prime}
\end{array}\right]=G_{n}^{-1}\left\{\left[\begin{array}{c}
i_{\text {dref }}(k+1) \\
i_{\text {qref }}(k+1)
\end{array}\right]-F_{n}\left[\begin{array}{c}
i_{d}(k) \\
i_{q}(k)
\end{array}\right]\right\},} \\
& V_{\text {qref }}=V_{\text {qref }}^{\prime}+\omega \psi \ldots \ldots \ldots \ldots \ldots \ldots \ldots \ldots \ldots \ldots \ldots \ldots \ldots \ldots
\end{aligned}
$$

3.3 Deadbeat Control with Disturbance Compensation (DBDC) To improve robustness against motor parameter variations, the disturbance compensation method was proposed for the deadbeat control. Where, the disturbance voltage $D_{d}$ and $D_{q}$ are defined as (8) and (9) as follows ${ }^{(10)}$.

$$
\begin{aligned}
& D_{d}=R_{n}\left(I_{\text {dref }}-I_{d}\right)-\omega L_{q n}\left(I_{\text {qref }}-I_{q}\right) \\
& D_{q}=R_{n}\left(I_{\text {qref }}-I_{q}\right)-\omega L_{d n}\left(I_{\text {dref }}-I_{d}\right)
\end{aligned}
$$

Equation (10) shows the state equation with the disturbance voltage $D_{d}, D_{q}$ on d-q coordination.

$$
\dot{x}=A_{n} x+A_{d} D+B_{n} u,
$$

where

$$
\begin{aligned}
& x=\left[\begin{array}{l}
i_{d} \\
i_{q}
\end{array}\right], D=\left[\begin{array}{l}
D_{d} \\
D_{q}
\end{array}\right], \\
& u=\left[\begin{array}{c}
V_{d} \\
V_{q}-\omega \psi
\end{array}\right], A_{n}=\left[\begin{array}{cc}
-\frac{R_{n}}{L_{d n}} & \frac{\omega L_{q n}}{L_{d n}} \\
-\frac{\omega L_{d n}}{L_{q n}} & -\frac{R_{n}}{L_{q n}}
\end{array}\right], \\
& A_{d}=\left[\begin{array}{cc}
\frac{1}{L_{d n}} & 0 \\
0 & \frac{1}{L_{q n}}
\end{array}\right], B_{n}=\left[\begin{array}{cc}
\frac{1}{L_{d n}} & 0 \\
0 & \frac{1}{L_{q n}}
\end{array}\right] . \cdots
\end{aligned}
$$

Based on (10), the discrete time model can be described as (12).

$$
x(k+1)=F_{n} x(k)+F_{d} D(k)+G_{n} u(k), \cdots
$$

where

$$
F_{n}=e^{A_{n} T}, F_{d}=e^{A_{d} T}, G_{n}=e^{\frac{A_{n} T}{2}} B_{n} .
$$

In (12), replacing $u(k)$ as $u_{r e f}(k)$ and replacing $x(k+1)$ as $x(k+1)$ as $x_{r e f}(k)$, the output voltage command $u_{r e f}(k)$ can be calculated as shown in (14).

$$
u_{r e f}(k)=G_{n}^{-1}\left\{x_{r e f}(k)-F_{n} x(k)-F_{d} D(k)\right\},
$$

where

$$
\left[\begin{array}{c}
V_{\text {dref }} \\
V_{\text {qref }}^{\prime}
\end{array}\right]=G_{n}^{-1}\left\{\left[\begin{array}{c}
i_{\text {dref }}(k+1) \\
i_{\text {qref }}(k+1)
\end{array}\right]-F_{n}\left[\begin{array}{c}
i_{d}(k) \\
i_{q}(k)
\end{array}\right]-F_{d}\left[\begin{array}{c}
D_{d}(k) \\
D_{q}(k)
\end{array}\right]\right\} .
$$




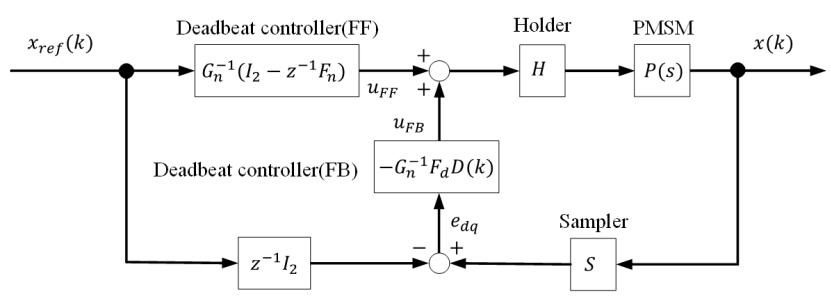

Fig. 4. Diagram of 2-degree-of-freedom control system

3.4 2-degree-of-freedom Deadbeat Control with Disturbance Compensation (2DOF-DBDC) In order to realize high tracking accuracy and robustness, 2-degree-offreedom deadbeat control system is composed of a conventional feedback deadbeat controller and a feedforward controller. Figure 4 shows the block diagram of the 2-degree-offreedom deadbeat control system for an IPMSM.

Equation (16) gives the output voltage of the feedforward controller using the reference current value. $I_{2}$ indicates the $2 \times 2$ identity matrix.

$$
u_{F F}=G_{n}^{-1}\left(I_{2}-z^{-1} F_{n}\right) x_{r e f}(k) \cdots \cdots \cdots \cdots \cdots \cdots
$$

The feedback controller calculates the output voltage, in order to control the current error to be zero by the deadbeat control method. The output voltage of the feedback controller can be obtained by (17).

$$
u_{F B}=-G_{n}^{-1} F_{d} D(k)
$$

In 2-degree-of-freedom deadbeat control method, the output voltage as shown in (18) that can be led from (16) and (17).

$$
u_{r e f}(k)=G_{n}^{-1}\left(x_{r e f}(k)-F_{n} x_{r e f}(k-1)-F_{d} D(k)\right),
$$

where

$$
\left[\begin{array}{l}
V_{\text {dref }} \\
V_{\text {qref }}^{\prime}
\end{array}\right]=G_{n}^{-1}\left\{\left[\begin{array}{c}
i_{\text {dref }}(k) \\
i_{\text {qref }}(k)
\end{array}\right]-F_{n}\left[\begin{array}{c}
i_{\text {dref }}(k-1) \\
i_{\text {qref }}(k-1)
\end{array}\right]-F_{d}\left[\begin{array}{c}
D_{d}(k) \\
D_{q}(k)
\end{array}\right]\right\} .
$$

\section{Stability Analysis}

To evaluate robustness against the parameter variations, stability analysis was considered. Equation (20) gives the poles of a closed loop for deadbeat control as follows.

$$
\text { pole }_{D B}=\operatorname{eig}\left(F-G G_{n}^{-1} F_{n}\right) .
$$

DBDC is a combination of deadbeat control and disturbance compensation control, thus, the poles of a closed loop for DBDC control can be expressed as (21).

$$
\text { pole }_{D B D C}=\operatorname{eig}\left(F-G G_{n}^{-1}\left(F_{n}+F_{d}\right)\right)
$$

In case of 2DOF-DB control, the deadbeat control is applied for the feedback controller, thus, the poles of a closed loop for 2DOF-DB control is expressed in (22) as same as (20), because the deadbeat feedback controller in 2DOF-DB is same configuration as the feedback controller for the DB control.

$$
\text { pole }_{2 D O F-D B}=\operatorname{eig}\left(F-G G_{n}^{-1} F_{n}\right) .
$$
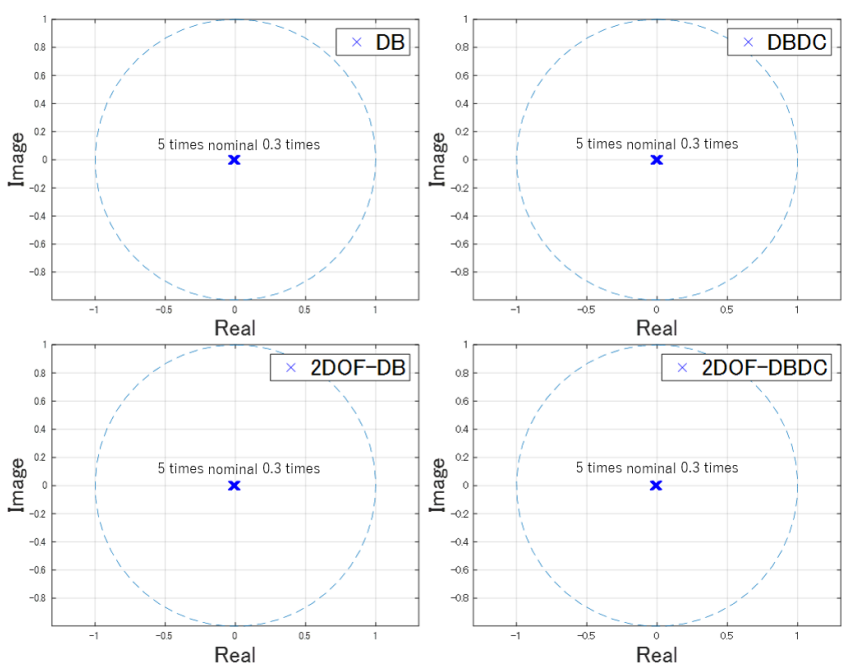

Fig. 5. Stability analysis against $\mathrm{R}$ variation
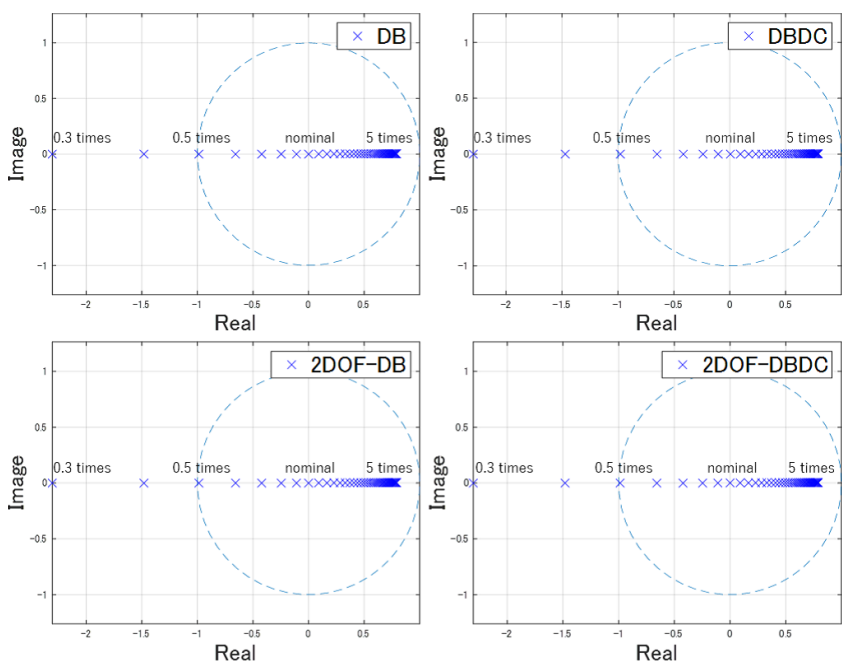

Fig. 6. Stability analysis against $\mathrm{L}$ variation

2DOF-DBDC control has the disturbance compensation method for a feedback controller, the poles of a closed loop for 2DOF-DBDC control can be expressed in (23).

$$
\text { pole }_{2 D O F-D B D C}=\operatorname{eig}\left(F-G G_{n}^{-1} F_{d}\right) .
$$

The results of stability analysis are shown in Fig. 5 and Fig. 6. Figure 5 shows the pole trajectory for $\mathrm{R}$ variations obtained from (20) (23), and the poles can be plotted around the origin. Thus, the systems are stable for $\mathrm{R}$ variations. Figure 6 shows the pole trajectory for $\mathrm{L}$ variations. In the case that $L$ is smaller than $50 \%$ of nominal value, the systems become unstable for each control method. However, the systems show the stable for $L$ variation from $50 \%$ to $500 \%$. From this analysis, the rather large error for the motor parameter identification can be acceptable for implementation, and also the parameter variation while the operation due to the motor temperature can be compensated.

\section{Simulation}

Table 1 shows the simulation conditions and Table 2 shows the parameters of an IPMSM used for the simulation.

5.1 Nominal Condition The motor speed was set to $200 \mathrm{rpm}$ and the reference current $I_{\text {dref }}$ was set to $0 \mathrm{~A}$. The 
Table 1. Simulation condition

\begin{tabular}{c|c}
\hline Parameter & Value \\
\hline \hline Sampring period & $50 \mu \mathrm{s}$ \\
Carrier frequency & $20 \mathrm{kHz}$ \\
Voltage of inverter & $70 \mathrm{~V}$ \\
Speed load & $200 \mathrm{rpm}$ \\
D-axis reference current & $0 \mathrm{~A}$ \\
Q-axis reference current & $1.5 \rightarrow 2.0 \mathrm{~A}$ \\
Simulation tools & MATLAB/Simulink \\
\hline
\end{tabular}

Table 2. IPMSM parameter

\begin{tabular}{c|c}
\hline Parameter & Value \\
\hline \hline Armature resistance $(R)$ & $1.44 \Omega$ \\
D-axis inductance $\left(L_{d}\right)$ & $6.9454 \mathrm{mH}$ \\
Q-axis inductance $\left(L_{q}\right)$ & $8.8403 \mathrm{mH}$ \\
D axis magnetic flux $(\psi)$ & $0.1563 \mathrm{~Wb}$ \\
Moment of interia $(J)$ & $2.0 \times 10^{-3} \mathrm{kgm}^{2}$ \\
Pole pairs $(P)$ & 4 \\
\hline
\end{tabular}

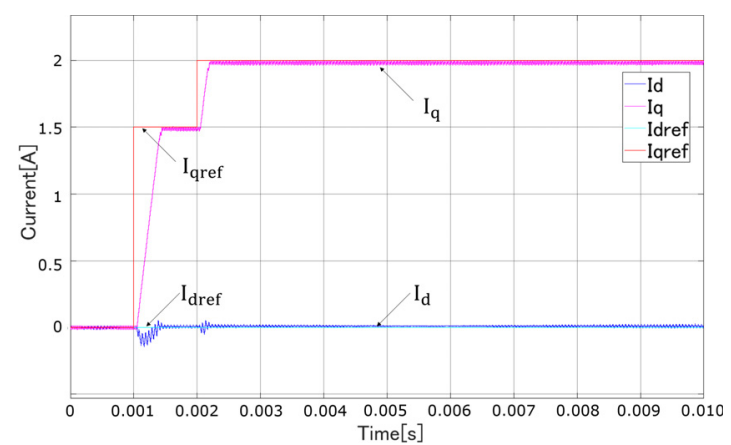

Fig. 7. Step response of the torque current (DB) (Nominal condition)

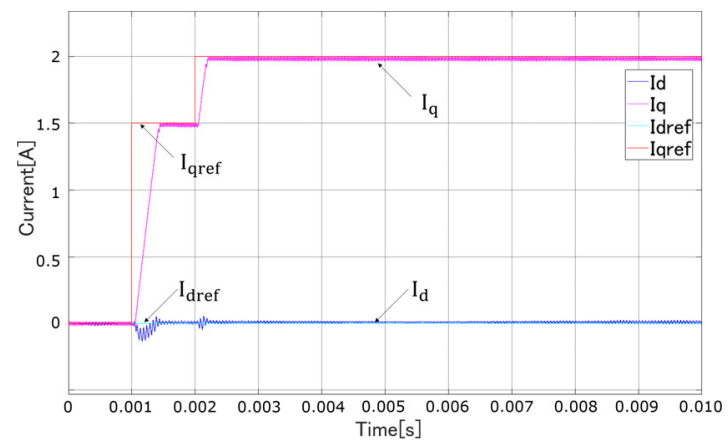

Fig. 8. Step response of the torque current (DBDC) (Nominal condition)

reference current $I_{\text {qref }}$ was varied from $1.5 \mathrm{~A}$ to $2.0 \mathrm{~A}$. The simulation results as current waveforms of $I_{d}$ and $I_{q}$ as torque current using the nominal motor parameters are shown from Fig. 7 to Fig. 10. The simulation results are summarized in Table 3 as step response time and steady state error of $I_{q}$. The results of current response $I_{q}$ could not be settled in one period of PWM carrier interval, because of the voltage limit of the inverter output. The step response time was measured as time from $1.5 \mathrm{~A}$ to $2.0 \mathrm{~A}$ with $5 \%$ band, because the current control error of $I_{d}$ could not affect $I_{q}$ response compared to initial step response from $0 \mathrm{~A}$ to $1.5 \mathrm{~A}$.

Table 3 shows that the simulation results of 2DOF-DB and 2DOF-DBDC have better error suppression performance in steady-state than that of DB and DBDC. The current response point of view, 2DOF-DB and 2DOF-DBDC are much improved compared with that of DB and DBDC, also. These simulation results show that 2-degree-of-freedom control method can improve the current response and the steadystate. In the nominal condition, the disturbance element is zero, therefore, the disturbance compensation method does not give any effectiveness for step response and steady state error.

5.2 Unnominal Condition Simulations for unnominal condition as the motor parameter variation were carried

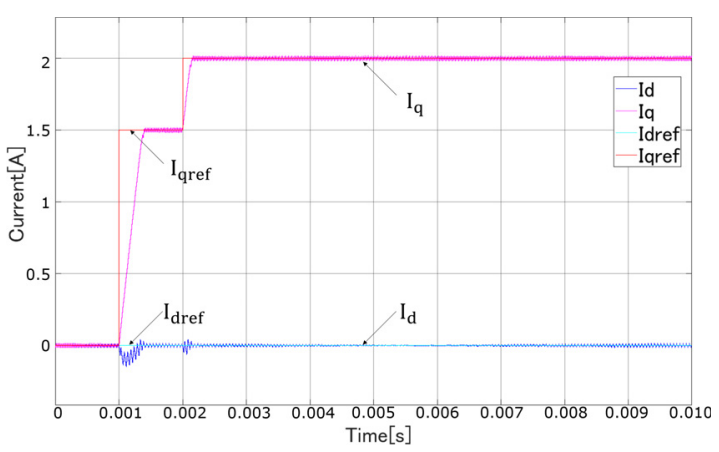

Fig. 9. Step response of the torque current (2DOF-DB) (Nominal condition)

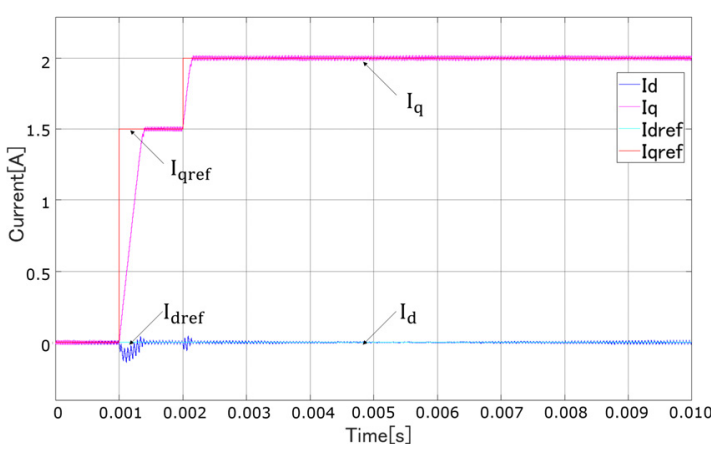

Fig. 10. Step response of the torque current (2DOFDBDC) (Nominal condition)

Table 3. Torque current characteristics (Nominal condition)

\begin{tabular}{c||c|c}
\hline Control method & Step response $(\mu \mathrm{s})$ & Steady state error $(\mathrm{mA})$ \\
\hline \hline DB & 215.8 & 17.0 \\
DBDC & 216.0 & 17.0 \\
2DOF-DB & 146.0 & 0.0 \\
2DOF-DBDC & 146.4 & 0.0 \\
\hline
\end{tabular}

out. Where, the motor parameters $L_{d}, L_{q}$, and $R$ were set to 0.5 times of the nominal value. The gain of 0.5 for the motor parameter was selected as minimum value from the result of stability analysis against $L$ variation. The motor speed reference was set to $200 \mathrm{rpm}$ and the reference current $I_{\text {qref }}$ was varied from $0 \mathrm{~A}$ to $1.5 \mathrm{~A}$, and from $1.5 \mathrm{~A}$ to $2.0 \mathrm{~A}$ as step response. The current waveforms of $I_{d}$ and $I_{q}$ with the unnominal motor parameters are shown from Fig. 11 to Fig. 14. The simulation results are summarized in Table 4 as step response time and steady state error of $I_{q}$.

Table 4 shows the simulation results of 2DOF-DB and 2DOF-DBDC have better error suppression performance in steady-state than that of DB and DBDC. 2DOF-DB and 2DOF-DBDC have better step response, also. The verification for the uninominal condition was carried out in the case that the motor parameter was varied from the nominal parameters initially. The disturbance element was not changed dynamically while the system operation. There is almost no difference between 2DOF-DB and 2DOF-DBDC using the disturbance compensation method.

\section{Experiment}

The experiment for this study used a FPGA Altera CycloneIII based hardware controller that can realize to complete all computation processing for motor control within the 


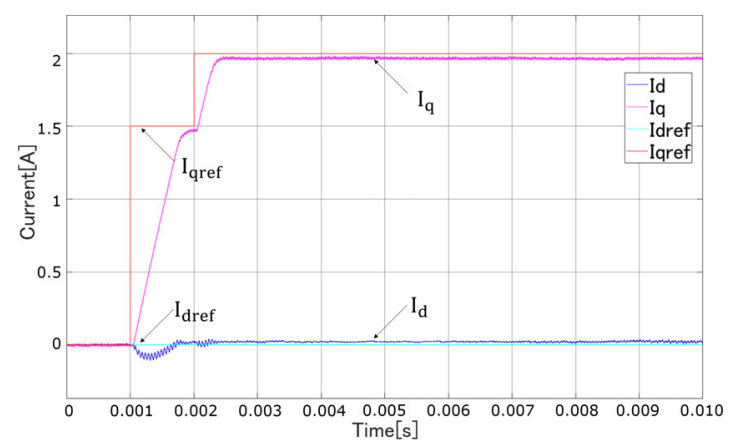

Fig. 11. Step response of the torque current (DB) (Unnominal condition)

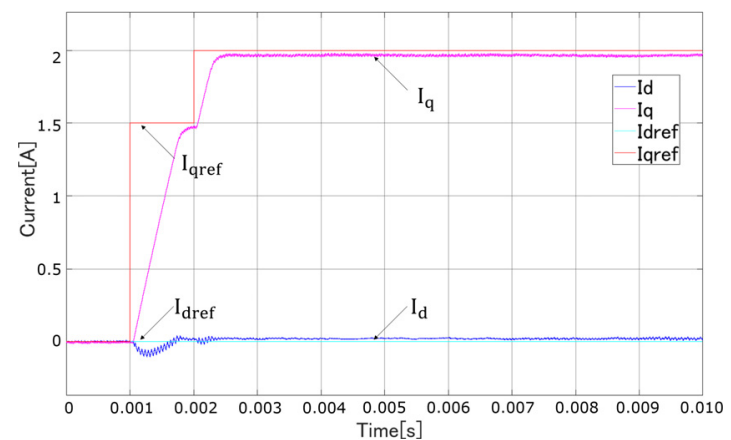

Fig. 12. Step response of the torque current (DBDC) (Unnominal condition)

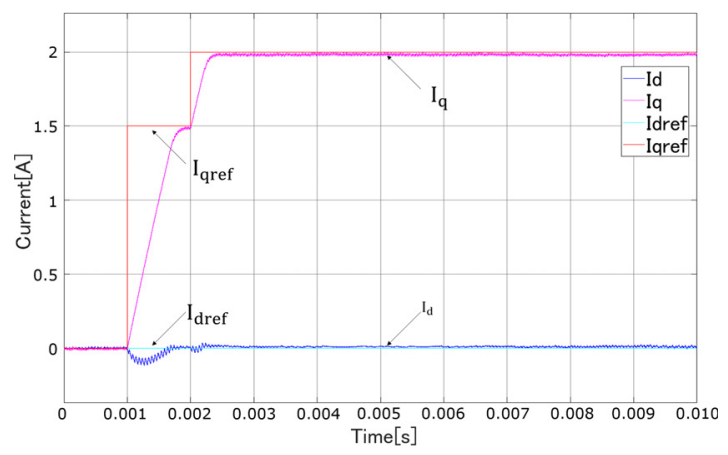

Fig. 13. Step response of the torque current (2DOF-DB) (Unnominal condition)

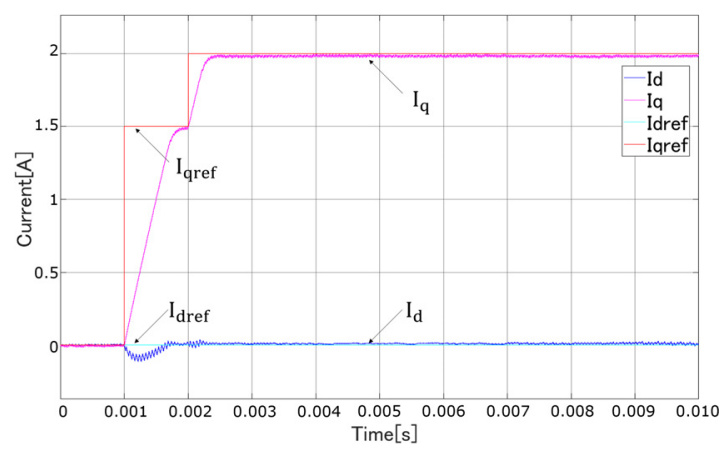

Fig. 14. Step response of the torque current (2DOFDBDC) (Unnominal condition)

dead time of the inverter. FPGA can perform parallel processing and minimize the sampling period and calculation time, then, ideal real-time feedback control without sample delay can be realized. On the other hand, a Digital signal processor (DSP) generally used for a controller of motor drive system
Table 4. Torque current characteristics (Unnominal condition)

\begin{tabular}{c||c|c}
\hline Control method & Step response $(\mu \mathrm{s})$ & Steady state error $(\mathrm{mA})$ \\
\hline \hline DB & 396.0 & 35.0 \\
DBDC & 416.0 & 35.0 \\
2DOF-DB & 366.0 & 19.0 \\
2DOF-DBDC & 367.0 & 19.0 \\
\hline
\end{tabular}

Table 5. Experimental condition Table 6. IPMSM parameter

\begin{tabular}{c|c}
\hline Parameter & Value \\
\hline \hline Sampring period & $50 \mu \mathrm{s}$ \\
Carrier frequency & $20 \mathrm{kHz}$ \\
Voltage of inverter & $70 \mathrm{~V}$ \\
Speed load & $200 \mathrm{rpm}$ \\
D-axis reference current & $0 \mathrm{~A}$ \\
Q-axis reference current & $1.5 \rightarrow 2.0 \mathrm{~A}$ \\
\hline
\end{tabular}

\begin{tabular}{c|c}
\hline Parameter & Value \\
\hline \hline Armature resistance $(R)$ & $1.44 \Omega$ \\
D-axis inductance $\left(L_{d}\right)$ & $6.9454 \mathrm{mH}$ \\
Q-axis inductance $\left(L_{q}\right)$ & $8.8403 \mathrm{mH}$ \\
D axis magnetic flux $(\psi)$ & $0.1563 \mathrm{~Wb}$ \\
Moment of interia $(J)$ & $2.0 \times 10^{-3} \mathrm{kgm}^{2}$ \\
Pole pairs $(P)$ & 4 \\
\hline
\end{tabular}

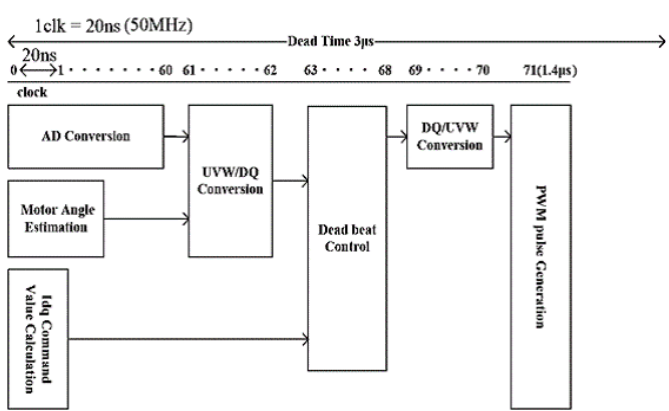

Fig. 15. Timing chart of processing by FPGA

can not give ideal real-time feedback control, because DSP is operated in sequential process and takes computation time that depends on the software volume and the processor capability. Table 5 shows the experimental conditions, and Table 6 shows the parameters of an IPMSM used for this experiment. The time chart of processing by a FPGA is shown in Fig. 15. The motor speed was controlled by load motor drive system using an IPMSM and its inverter, and the motor speed reference was set as $200 \mathrm{rpm}$ shown in Table 5. D-axis current reference $I_{d r e f}$ was set as $0 \mathrm{~A}$, and Q-axis current reference $I_{\text {qref }}$ was changed from $0 \mathrm{~A}$ to $1.5 \mathrm{~A}$ and from $1.5 \mathrm{~A}$ to $2.0 \mathrm{~A}$, as step response. The test was done for each control method, DB, DBDC, 2DOF-DB and 2DOF-DBDC.

6.1 Nominal Condition From Fig. 16 to Fig. 19 show the experimental results of current waveforms with the nominal motor parameters of an IPMSM. Step response time was measured from changing timing of current command to $2.0 \mathrm{~A}$ with $5 \%$ band. Since the large measurement noise, the step response time could not be measured as settling time in general. Table 7 summarizes the torque current characteristics as Q-axis current step response and the steady state error as averaged value after step response. These results show that applying 2 degree of freedom control can improve the step response. As Table 7, 2DOF-DB of $59.0 \mu$ s as step response was much shorter than DB of $112.5 \mu \mathrm{s}$, and 2DOF-DBDC of $55.5 \mu \mathrm{s}$ was also much shorter than DBDC of $98.0 \mu \mathrm{s}$. From comparison between DB and DBDC, or between 2DOF-DB and 2DOF-DBDC in Table 7, the disturbance compensation control method gives slightly better performance in step response. This result can be considered that the minor difference between the nominal parameter and the actual motor parameter could be compensated by the disturbance compensation control method. 


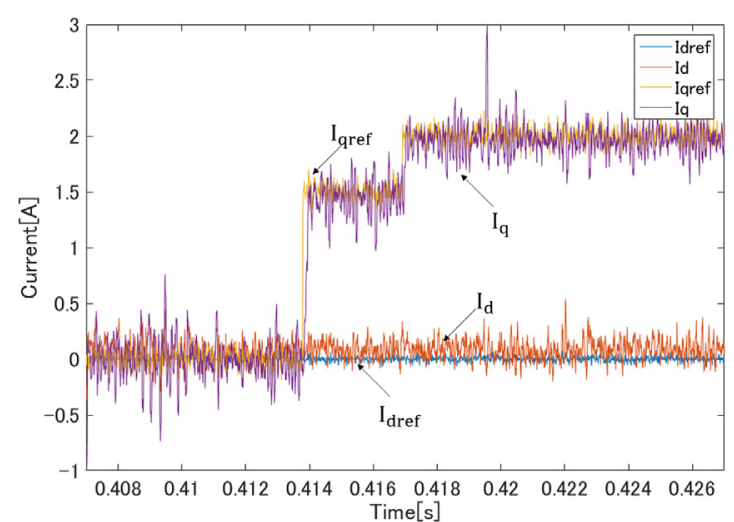

Fig. 16. Step response of the torque current (DB) (Nominal condition)

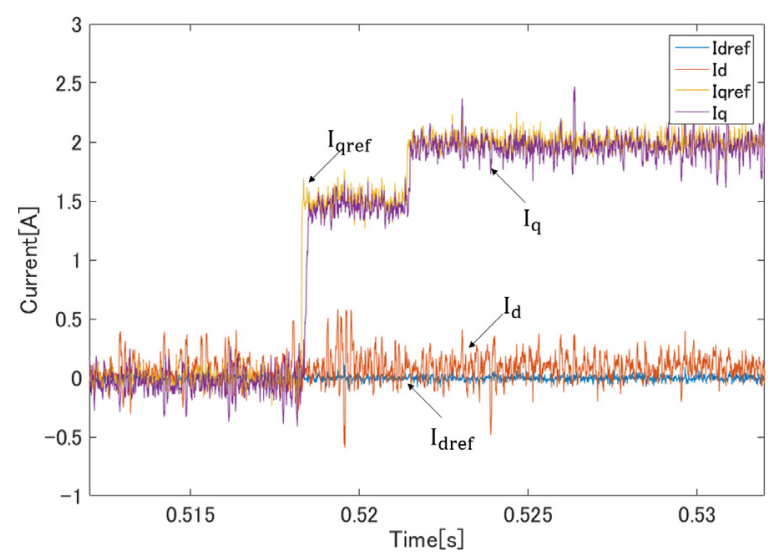

Fig. 17. Step response of the torque current (DBDC) (Nominal condition)

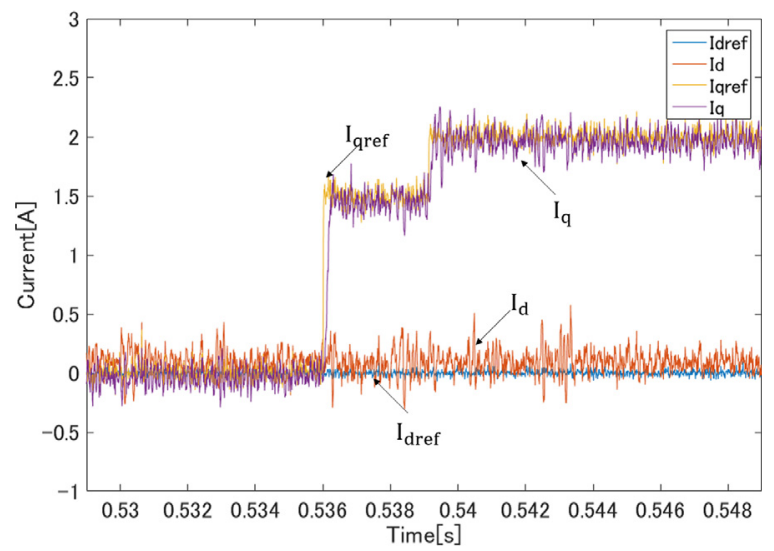

Fig. 18. Step response of the torque current (2DOF-DB) (Nominal condition)

6.2 Unnominal Condition In order to verify the robustness of controllers against for the motor parameters variations, the control gains calculated using the half value of the nominal motor parameters, as $L_{d}, L_{q}$, and R were set in each control method. This controller condition can validate the motor parameters variations as simple and equivalent approach, without any changing the motor hardware.

From Fig. 20 to Fig. 23 show the experimental results of current waveforms with the unnominal motor parameters of an IPMSM. Table 8 summarizes the torque current characteristics as Q-axis current step response and steady state error.

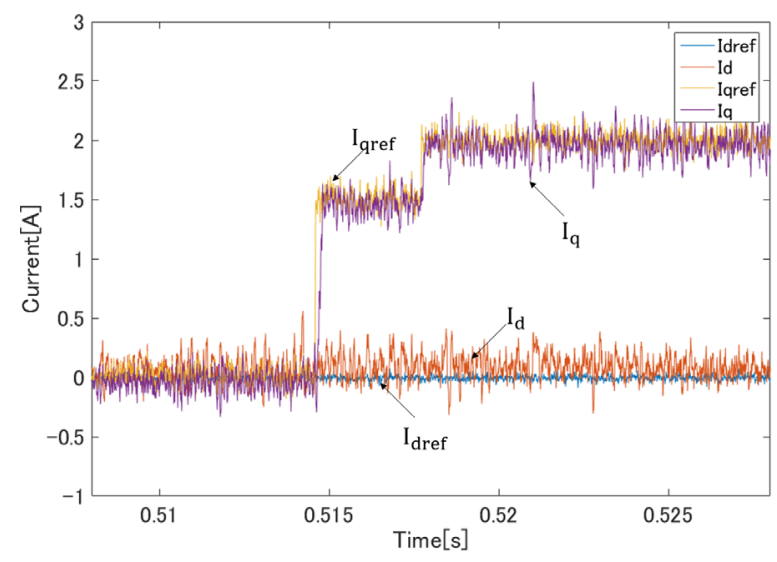

Fig. 19. Step response of the torque current (2DOFDBDC) (Nominal condition)

Table 7. Torque current characteristics (Nominal condition)

\begin{tabular}{c||c|c}
\hline Control method & Step response $(\mu \mathrm{s})$ & Steady state error $(\mathrm{mA})$ \\
\hline \hline DB & 112.5 & 148 \\
DBDC & 98.0 & 147 \\
2DOF-DB & 59.0 & 148 \\
2DOF-DBDC & 55.5 & 150 \\
\hline
\end{tabular}

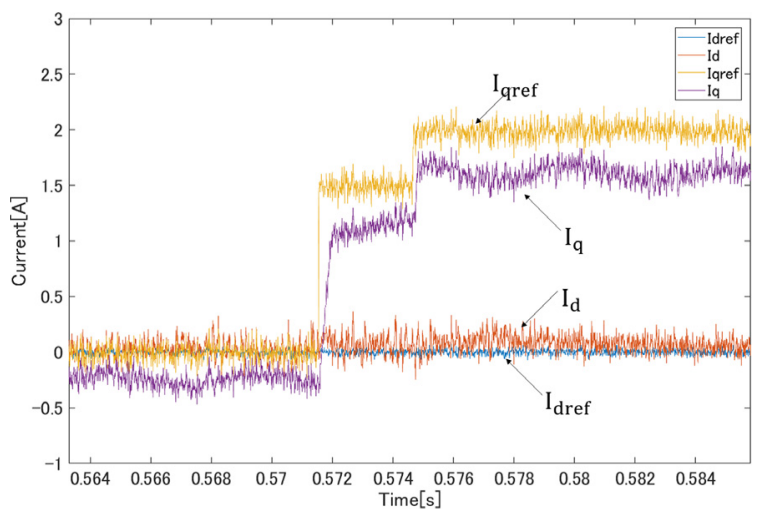

Fig. 20. Step response of the torque current (DB) (Unnominal condition)

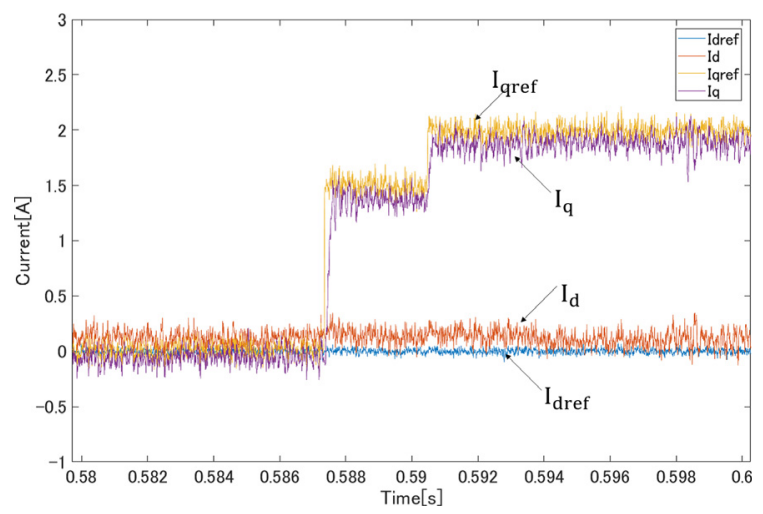

Fig. 21. Step response of the torque current (DBDC) (Unnominal condition)

From Fig. 20 as current waveforms, DB does not have sufficient performance against the motor parameter variation apparently in step response and steady state error. Applying disturbance compensation control method, the result of DBDC as Fig. 21 shows that the steady state error can be suppressed. 


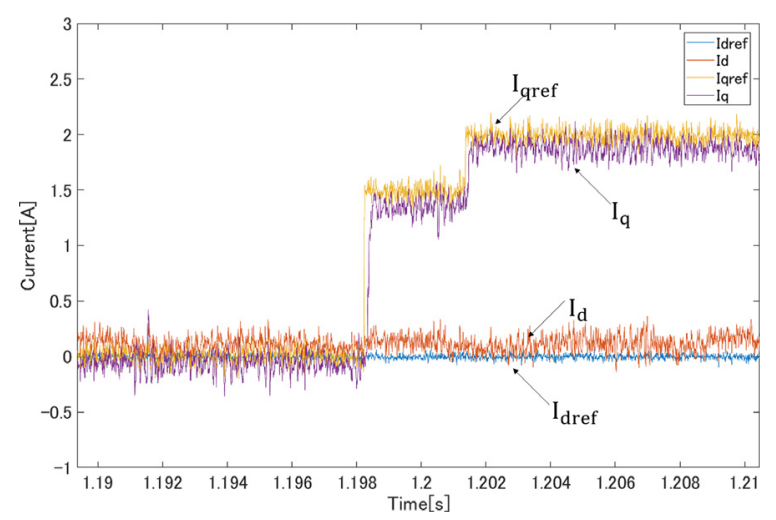

Fig. 22. Step response of the torque current (2DOF-DB) (Unnominal condition)

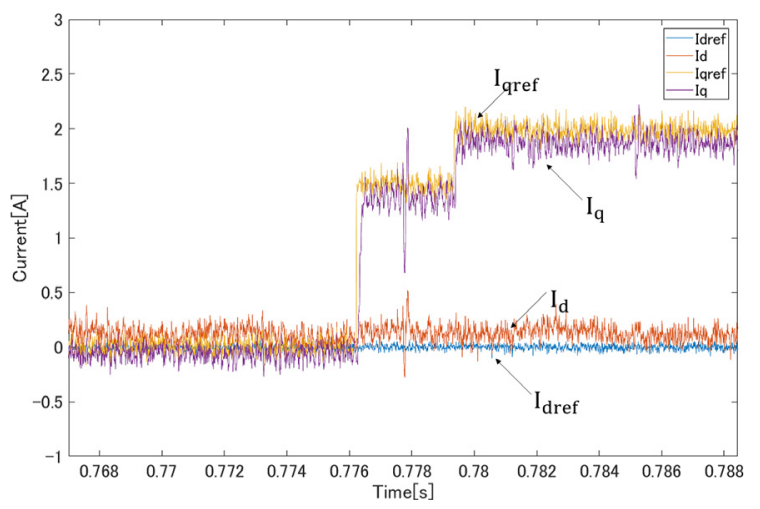

Fig. 23. Step response of the torque current (2DOFDBDC) (Unnominal condition)

Table 8. Torque current characteristics (Unnominal condition)

\begin{tabular}{c||c|c}
\hline Control method & Step response $(\mu \mathrm{s})$ & Steady state error $(\mathrm{mA})$ \\
\hline \hline DB & $(166.5)^{*}$ & 379 \\
DBDC & 139.5 & 176 \\
2DOF-DB & 82.0 & 159 \\
2DOF-DBDC & 49.5 & 159 \\
\hline
\end{tabular}

${ }^{*}$ DB could not settle in $\pm 5 \%$ of the current command.

Also, the step response of DBDC was observed more shorter than that of DB. The current response of DB could not settle in $\pm 5 \%$ of the current command, then, the step response time was measured as time from changing timing of current command to averaged value of $I_{q}$.

These experimental results show large measurement noise, then, it is difficult to validate absolute value of step response time including comparison with simulation results. However, the step response and the steady state error point of view, 2 degree of freedom controls as 2DOF-DB and 2DOF-DBDC show better performance. Especially, the proposed 2DOFDBDC shows good control performance in the step response error and the steady response error, even in the condition of motor parameter variations and the other disturbance like as dead time of the inverter. From these test results, the proposed 2DOF-DBDC shows good control performance in the step response and the steady state error, even in the condition of motor parameter variations.

\section{Conclusion}

This paper proposed the motor control system for a PMSM applying 2-degree-of-freedom deadbeat control with a disturbance compensation method realized by a FPGA hardware controller. The effectiveness of the proposed control system was verified through simulations and experiments, and the results showed that the proposed control system can improve control performance in step response and steady state error, robustness against parameter variations.

\section{References}

( 1 ) R. Tanabe and K. Akatsu: "Advanced Torque and Current Control Techniques for PMSMs with a Real-time Simulator Installed Behavior Motor Model", IEEJ Journal of Industry Applications, Vol.5, No.2, pp.167-173 (2016)

( 2 ) R. Tanabe and K. Akatsu: "Advanced Torque Control of Permanent Magnet Synchronous Motor Using Finite Element Analysis Based Motor Model with a Real-time Simulator", IEEJ Journal of Industry Applications, Vol.6, No.3, pp.173-180 (2017)

( 3 ) K. Matsuura, Y. Akama, K. Abe, K. Ohishi, H. Haga, and I. Ando: "Fine Three-Phase Current Reconstruction based on Calculating the Phase-Shifted Voltage Reference Using Only the DC Current Sensor of an Inverter and Its Application to a PM Motor Drive", IEEJ Journal of Industry Applications, Vol.6, No.1, pp.58-65 (2017)

( 4 ) T. Miyajima, H. Fujimoto, and M. Fujitsuna: "Control Method for IPMSM Based on Perfect Tracking Control and PWM Hold Model in Overmodulation Range", in Proc. The 2010 International Power Electronics Conference -ECCE ASIA- IPEC-Sapporo 2010 PROCEEDINGS, Sapporo, Japan, pp.593-598 (2010)

( 5 ) T. Miyajima, H. Fujimoto, and M. Fujitsuna: "Control Method for IPMSM Based on PTC and PWM Hold Model in Overmodulation Range -Study on Robustness and Comparison with Anti-Windup Control-", in Proc. The 2010 IEEE Energy Conversion Congress and Exposition proceedings, Atlanta, USA, pp.2844-2850 (2010)

( 6 ) T. Miyajima, H. Fujimoto, and M. Fujitsuna: "Control method for IPMSM based on perfect tracking control and PWM hold model in overmodulation range", IEEJ Trans. IA, Vol.130, No.10, pp.1153-1160 (2010) (in Japanese)

( 7 ) H. Uchida and T. Yokoyama: "1 MHz Variable Sampling Deadbeat Control of Single Phase PWM Inverter", Proceedings of the IEE Japan Industry Applications Society Conference, Vol.2012, No.1, pp.111-114 (2012) (in Japanese)

( 8 ) A. Kitada and T. Yokoyama: "Precise torque control for interior permanent magnet synchronous motor using FPGA based hardware controller", GCC Conference and Exhibition (GCC) (2013)

( 9 ) A. Kitada,K. Miyata, K. Tsuchiya, H. Sato, and T. Yokoyama: "1 MHz Variable Sampling Deadbeat Control for PM motor using FPGA", Power Electronics and ECCE Asia (ICPE-ECCE Asia), Seoul, South Korea (2015)

(10) K. Miyata and T. Yokoyama: "A Study of $1 \mathrm{MHz}$ Multi-Sampling Deadbeat Control with Disturbance Compensation for PMSM Drive System using FPGA", IPEMC 2016-ECCE Asia, Hefei City, China (2016)

(11) K.P. Gokhale, A. Kawamura, and R.G. Hoft: "Deadbeat microprocessor control of PWM inverter for sinusoidal output waveform synthesis", IEEE Trans. Industry Applications, Vol.IA-23, No.5, pp.901-910 (1985)

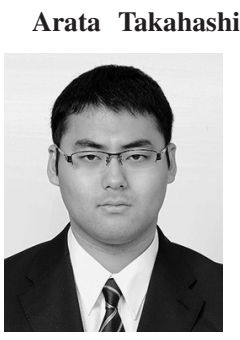

(Student Member) received the B.S. degree in Robot Mechatronics from Tokyo Denki University, Tokyo, Japan, in 2018. His research interests are in the areas of advanced control of power electronics. Mr. Takahashi is a student member of the Institute of Electrical Engineers of Japan.

Kazuya Ito (Student Member) received the B.S. degree in Robot

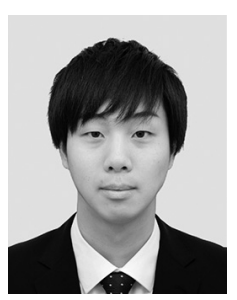
Mechatronics from Tokyo Denki University, Tokyo, Japan, in 2019. His research interests are in the areas of advanced control of power electronics. Mr. Ito is a student member of the Institute of Electrical Engineers of Japan. 
Kantaro Yoshimoto (Member) received the B.S., M.S., and Ph.D. ?. from Yokohama National University, Yokohama, Japan, in 1997, 1999, and 2010 respectively. In 2001, he joined NISSAN Motor Co., Ltd. He performed research in power electronics, and development of control system for electric vehicles and hybrid electric vehicles. Since 2020, he is an Associate Professor with Tokyo Denki University, Tokyo and his general interests include power electronics, motor drive and electric vehicles.
Tomoki Yokoyama (Member) received the B.S., M.S. and Ph.D. de-

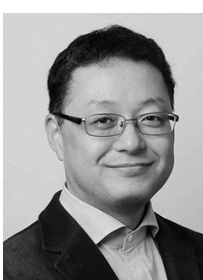
grees in Electrical Engineering from Yokohama National University, Kanagawa, Japan, in 1988 and 1994, respectively. In 1994, he joined Toshiba Corporation Japan. In 1998, he joined Tokyo Denki University. He is currently a professor. His research interests are in the areas of advanced control of power electronics. Prof. Yokoyama is a member of the Institute of Electrical Engineers of Japan and IEEE. 